\title{
IT and Knowledge Management Influence on Organizational Learning Capability_-The Mediating Role of Organic Structures
}

\author{
Katarzyna Tworek, Katarzyna Walecka-Jankowska, Anna Zgrzywa-Ziemak, Janusz Martan \\ Wrocław University of Technology, Wrocław, Poland
}

\begin{abstract}
This article describes a valid and current research area, which is the formation of organizational learning ability, perceived as a condition necessary for the survival and development of modern organizations. It refers to the issue of organic organizational structure as a factor shaping this ability. Many researchers emphasized that the organizational structure plays a key role in determining the processes of organizational learning. However, only in recent years, these views have been verified empirically_demonstrating the importance of organic structures in this area. Therefore, determination of what may contribute to the development of organic structural solutions in the context of developing learning capacity of the company appears to be a significant research problem. This article discusses what is the organic organizational structure role in shaping the learning ability of organization. It was empirically verified, using confirmation factor analysis, that among other factors organic structure determines organizational learning capability (OLC). Next part of article describes information technology (IT) and knowledge management $(\mathrm{KM})$ as two important factors influencing structure reorganization and facilitating introduction of organic-type structure in organization. Discussion concerning the problem of their influence on various organizational structure dimensions is included. After that, research results are presented. First part of these researches concerns IT and KM influence on organizational structure and provides conclusions based on correlation and stepwise regression analysis. The empirical results show that IT and KM are two important factors influencing structure reorganization and facilitating introduction of organic-type structure in organization. Research has shown that these factors are complementary in terms of their impact on the organizational structure (they have a statistically significant impact on various structural dimensions). Therefore, IT and KM may be considered as intermediate factors influencing OLC and should be closely observed in those organizations, which are trying to enhance their learning capability.
\end{abstract}

Keywords: information technology, knowledge management (KM), organic organizational structure, organizational learning capability (OLC)

\section{Introduction}

Functioning in a complex, dynamic, and intermittent environment forces to seek sources of competitive advantage not in specific products, technologies, or sources of resources, but in the ability of the organization to

Katarzyna Tworek, Ph.D., Eng., Wrocław University of Technology, Wrocław, Poland.

Katarzyna Walecka-Jankowska, Ph.D., Eng., Wrocław University of Technology, Wrocław, Poland.

Anna Zgrzywa-Ziemak, Ph.D., Eng., Wrocław University of Technology, Wrocław, Poland.

Janusz Martan, Ph.D., Eng., professor, Wrocław University of Technology, Wrocław, Poland.

Correspondence concerning this article should be addressed to Katarzyna Tworek, wyb. Wyspiańskiego 27, 50-370 Wrocław, Poland. E-mail: katarzyna.tworek@pwr.edu.pl. 
develop more and more new and useful knowledge (Wu, 2010). Organizational learning, learning faster and more efficient than the competition, is a prerequisite for survival and development of organizations (Santos-Vijande, López-Sánchez, \& Trespalacios, 2012). Empirical studies, carried out in different types of organizations operating in different industries, cultural contexts, and a number of other situational conditions, demonstrate the positive impact of organizations' learning on organizational performance and innovativeness (Goh, Elliott, \& Quon, 2012). The article focuses on the problem of developing the organizational learning capability (OLC).

OLC is defined as "the readiness of the organization to change its knowledge", where change of knowledge is perceived in the context of two parallel processes - the verification of the existing knowledge and the development of the new one (Zgrzywa-Ziemak, 2009, p. 34). OLC refers to the widely used by researchers concepts - organizational learning and learning organization. Although their comprehensive definition is beyond the scope of this study, it should be pointed out that "a learning organization is the ultimate goal that an organization strives to achieve, whereas organizational learning is the means through which a learning organization is attained; learning organization is the normative facet of organizational learning" (Karkoulian, Messarra, \& Mccarthy, 2013, p. 513). OLC refers to the potential of organizations to learn, not to the course of specific processes of organizational learning. The inspiration for building the concept of OLC is the learning organizations concepts. However, they focus primarily on the vision of a perfect organization (in which direction all organizations should develop) and OLC is based on the assumption that all organizations learn while possessing different learning capability. In this context, it is assumed that on one extreme, there are organizations with the lowest ability to learn - those close to the Weberian bureaucracy. On the other extreme, the organizations learning potentially the most efficiently are those that are constantly verifying the existing ways of working and thinking and are so perfect in developing new knowledge, that they constantly transform themselves according to the needs of the environment and their own aspirations. The functioning organizations in fact have the capability to learn somewhere among the outlined extremes. OLC is not a directly observable phenomenon, but it can be diagnosed and evaluated by the factors shaping it, and improved through these factors.

Since the breakthrough work by Fiol and Lyles (1985) on the nature of organizational learning, many researchers emphasized the fact that the organizational structure plays a key role in determining the processes of organizational learning. However, only in recent years, these views have been empirically verified and the importance of organic structures in this area was demonstrated (Zgrzywa-Ziemak, 2009; Martínez-León \& Martínez-García, 2011; Hao, Kasper, \& Muehlbacher, 2012; Mehrabi, Soltani, Alemzadeh, \& Jadidi, 2013). Therefore, determination of what may contribute to the development of organic structural solutions in the context of developing learning capacity of the company should be considered as an important research problem.

In the article, the empirical research results regarding the organic structure as an important factor influencing the learning of organizations are presented. The contribution of organic structure in OLC model proposed by Zgrzywa-Ziemak (2009) is discussed. To the researchers' knowledge, no other study has empirically tested the dependency between structure and OLC, but there are farther studies on the relationship between structure and organizational learning and learning organizations cited in the paper. In the second part of paper, authors identified two phenomena facilitating the introduction of organic-type structure in 
organization - information technology (IT) and knowledge management (KM). Restricting these two issues proves certain selectivity in the context of the wider problem, which is the formation of organizational structures. At the same time, however, the selected instruments are of particular importance for the learning organization. In organizations with the highest learning capability, it is necessary to ensure that all participants have access to information and knowledge, that there are implemented methods and techniques supporting the processes of developing and verifying the organizational knowledge and supporting the usage of new knowledge. Therefore, the next part of the article describes IT and KM as being crucial for structure reorganization for OLC development.

\section{Organic Organizational Structures Supporting Organizational Learning Capability}

Fiol and Lyles (1985) argued that the organizational structure allows both innovation and new insights, so it is an essential contextual factor that affects the probability that learning will occur at all. Organizational structure is seen as a kind of basis for organizational learning, which designs ways of acquiring information about the world and improving what the organization is able to do (Popper \& Lipshitz, 1998). According to Sakalas and Venskus (2007), the concept of quickly changing, learning organization is impossible to realize without respective organization management structures. Dodgson (1993) defined a learning organization as the one which deliberately adopts such structures and strategies to stimulate learning. According to Martínez-León and Martínez-García (2011), the OLC is influenced by structures, because the organizational structure influences the information flows and it plays a fundamental role in a company's capacity to identify the knowledge sources needed, acquiring new knowledge, integrating it into the organization, and recognizing its absorptive capacity.

It is crucial to define what kind of structures will be better for an organization that wants to enhance their learning capability. The typology proposed by containing "mechanistic" and "organic" organizations can be used for this purpose (Burns \& Stalker, 1961). Their idea was based on the fact that organizations can belong to one of the two main types: mechanistic (more complex and hierarchical structure, suited to stable conditions) and organic (more flat and fluent structure, adapting to conditions of rapid change and innovation). It can be concluded that these two types of organization are operating based on two completely different specific types of organizational structure.

Therefore, it is worth looking at the organization in the context of OLC and defining which one of these structures will be better for an organization that wants to enhance their learning capability.

Mechanistic structures have supported the learning of organizations in the Industrial Era by the implementation of learning from experience in routine operations. Such structures were homogeneous in nature and were relatively stable and univariate. Due to the complexity and dynamism of the reality in which contemporary organizations operate, the structures conducive to learning should be neither homogeneous nor stable.

Several authors over the years tried to overcome this challenge with different structural ideas. Nonaka and Takeuchi (1995) said that hypertext structure is probably the most known one — as the most advantageous for permanent and effective organizational knowledge creation. But there are also modular structure forms (Galunic \& Eisenhardt, 2001), project structure forms (DeFillippi, 2002), network structures (Martínez-León \& Martínez-García, 2011), or new economy structures (Lazonick, 2005). But all these ideas have one thing in common - the authors proposed organizational structures that are more flexible, flat, and adaptive. 
Proposed solutions usually facilitate departure from the principle of hierarchy and question the classical principle of unity of command and Taylor's division of employees to the conceptual and executive ones. These rules are eliminated for the benefit of control and coordination within the horizontal complex relationships between individuals and cooperative relations. Hierarchy of tasks, determined by their range, is more important than hierarchy of organizational power. There is a decentralization of decision-making authority, individuals, and organizational units that have considerable autonomy. There is also a disappearance of functional specialization in favor of a specialization of objective nature, focusing on the implementation of a specific task.

Therefore, it seems that behind different names and proposals presented by each author, the general idea is the same. Structures facilitating OLC in organizations should be as organic as it is possible. Since there are not many reliable papers available on that topic, it seems to be interesting to explore what factors can influence organizational structure, facilitating its reorganization to more organic-type one- better suited for organizations wanting to enhance their learning capability.

The research of Zgrzywa-Ziemak (2009) proves that organizational structure is one of the factors determining the OLC. The main aim of the study was the identification of factors structure of the OLC. Determining factors were theoretically identified and defined. Hypotheses about the structure of each factor and the structure of OLC were advanced. The theoretical model was empirically verified on a sample of 212 different (due to the industry and the size and form of ownership) organizations. Model verification was performed using the confirmatory factor analysis (SPSS AMOS was used). Figure 1 includes an OLC model. Tables 1 and 2 present chosen estimates of OCL model. The theoretical structure of the phenomenon was predominantly empirically confirmed. According to the measures of adjustment of the model to the data, it must be considered acceptable in view of three criteria $\left[x^{2} / \mathrm{ss}\right.$, RMSEA, and $P($ RMSEA $\left.<0.05)\right]$. Goodness of fit indices $(\mathrm{GFI}=0.864$ and AGFI $=0.831)$ does not exceed the recommended minimum of 0.9 , however, such a situation can occur when the model is very complex (it is a "punishment" for increasing the number of model parameters). The enterprise's learning capability is multidimensional phenomenon, which can be measured by 10 factors, the factor structure of the OLC points to two-seemingly contradictory-perspectives of this phenomenon: On one hand, it is shaped by the factors responsible for the permanent change of the organization; on the other, certain aspects responsible for the continuity of its duration are important.

According to the model, the higher the OLC is, the more the structural solutions are moving towards organic solutions (on a continuum from a mechanistic model to the organic model). In particular, the higher the OLC is and the lower the degree of standardization and formalization is, the more the horizontal interaction dominates in the communication, coordination, and control, the more the hierarchy of objectives dominates over the hierarchy of positions. The study has shown that the degree of specialization and centralization is not relevant for the studied phenomenon. Although contribution of the organizational structure in determining of the OLC is the lowest relative to other factors, since standardized regression weight is 0.56 (Figure 1) and the percentage of the explained variance is 0.310 (Table 2), it is a statistically significant factor in the structure of the OLC (Table 1). Subsequent studies on the relationship between organizational structure and the learning of the organization, though quite limited, confirm the nature of organic structural solutions for organizational learning (including centralization and specialization dimension). 


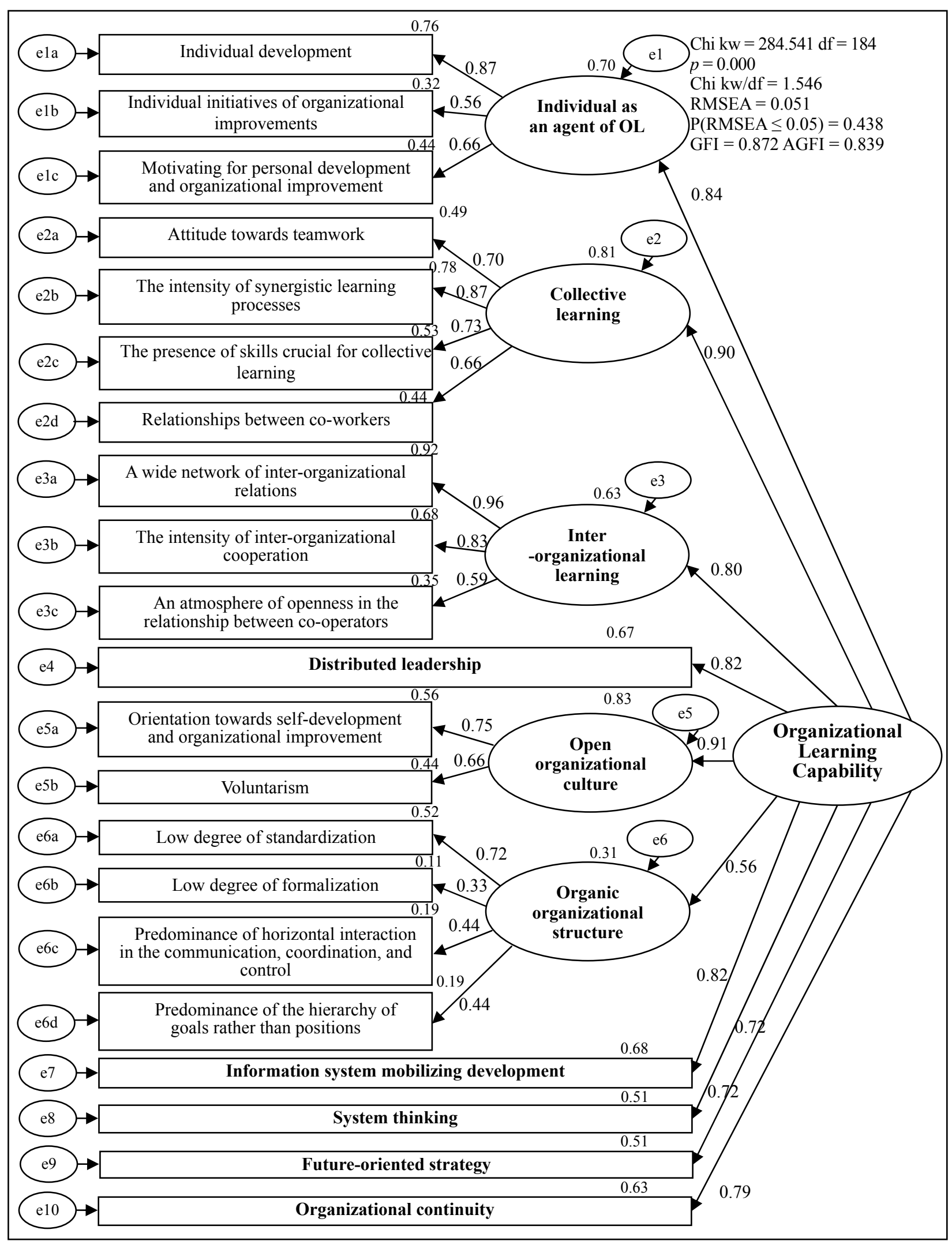

Figure 1. Path diagram model of confirmatory factor analysis for scales measuring the OLC $(n=212)$. Source: Zgrzywa-Ziemak (2009). 
Table 1

Estimates of OCL Model: Regression Weights

\begin{tabular}{|c|c|c|c|c|c|c|}
\hline & & & Estim. & S.E. & C.R. & $P$ \\
\hline Individual as agent of OL & $<---$ & OLC & 1.000 & & & \\
\hline Collective learning & $<---$ & OLC & 1.526 & 0.346 & 4.406 & $* * *$ \\
\hline Inter-organizational learning & $<---$ & OLC & 0.880 & 0.200 & 4.405 & $* * *$ \\
\hline Distributed leadership & $<---$ & OLC & 4.797 & 0.929 & 5.166 & $* * *$ \\
\hline Open organizational culture & $<---$ & OLC & 1.010 & 0.195 & 5.168 & $* * *$ \\
\hline Organic organizational structure & $<---$ & OLC & 0.250 & 0.063 & 3.960 & $* * *$ \\
\hline Information system mobilizing development & $<---$ & OLC & 3.955 & 0.711 & 5.564 & $* * *$ \\
\hline System thinking & $<---$ & OLC & 1.408 & 0.294 & 4.786 & $* * *$ \\
\hline Future-oriented strategy & $<---$ & OLC & 1.892 & 0.402 & 4.702 & $* * *$ \\
\hline Organizational continuity & $<---$ & OLC & 0.412 & 0.084 & 4.928 & $* * *$ \\
\hline Individual development & $<---$ & Individual as agent of $\mathrm{OL}$ & 1.243 & 0.225 & 5.519 & $* * *$ \\
\hline $\begin{array}{l}\text { Individual initiatives of organizational } \\
\text { improvements }\end{array}$ & $<---$ & Individual as agent of $\mathrm{OL}$ & 1.000 & & & \\
\hline $\begin{array}{l}\text { Motivating for personal development and } \\
\text { organizational improvement }\end{array}$ & $<---$ & Individual as agent of $\mathrm{OL}$ & 1.131 & 0.210 & 5.398 & $* * *$ \\
\hline Attitude towards teamwork & $<---$ & Collective learning & 0.507 & 0.097 & 5.233 & $* * *$ \\
\hline The intensity of synergistic LP & $<---$ & Collective learning & 2.095 & 0.347 & 6.032 & $* * *$ \\
\hline $\begin{array}{l}\text { The presence of skills crucial for collective } \\
\text { learning }\end{array}$ & $<---$ & Collective learning & 0.489 & 0.098 & 4.976 & $* * *$ \\
\hline Relationships between co-workers & $<---$ & Collective learning & 1.000 & & & \\
\hline A wide network of inter-organizational relations & $<---$ & Inter-organizational learning & 1.298 & 0.263 & 4.925 & $* * *$ \\
\hline $\begin{array}{l}\text { The intensity of inter-organizational } \\
\text { cooperation }\end{array}$ & $<---$ & Inter-organizational learning & 1.000 & & & \\
\hline $\begin{array}{l}\text { An atmosphere of openness in the relationship } \\
\text { between co-operators }\end{array}$ & $<---$ & Inter-organizational learning & 2.913 & 0.338 & 8.619 & $* * *$ \\
\hline $\begin{array}{l}\text { Orientation towards self-development and } \\
\text { organizational improvement }\end{array}$ & $<---$ & Open org. culture & 0.714 & 0.135 & 5.275 & $* * *$ \\
\hline Voluntarism & $<---$ & Open org. culture & 1.000 & & & \\
\hline Low degree of standardization & $<---$ & Organic org. structure & 1.000 & & & \\
\hline Low degree of formalization & $<---$ & Organic org. structure & 1.086 & 0.454 & 2.390 & 0.017 \\
\hline $\begin{array}{l}\text { Predominance of horizontal interaction in the } \\
\text { communication and coordination }\end{array}$ & $<---$ & Organic org. structure & 0.590 & 0.191 & 3.086 & 0.002 \\
\hline $\begin{array}{l}\text { Predominance of the hierarchy of goals rather } \\
\text { than positions }\end{array}$ & $<---$ & Organic org. structure & 0.583 & 0.179 & 3.256 & 0.001 \\
\hline
\end{tabular}

Table 2

Estimates of OCL Model: Squared Multiple Correlations

\begin{tabular}{ll}
\hline & Estimate \\
\hline Individual as agent of OL & 0.699 \\
Collective learning & 0.811 \\
Inter-organizational learning & 0.635 \\
Distributed leadership & 0.665 \\
Open organizational culture & 0.834 \\
Organic organizational structure & 0.310 \\
Information system mobilizing development & 0.679 \\
System thinking & 0.512 \\
Future-oriented strategy & 0.511 \\
Organizational continuity & 0.625 \\
Individual development & 0.758 \\
\hline
\end{tabular}


Table 2 continued

\begin{tabular}{ll}
\hline & Estimate \\
\hline Individual initiatives of organizational improvements & 0.317 \\
Attitude towards teamwork & 0.494 \\
The intensity of synergistic learning processes & 0.764 \\
The presence of skills crucial for collective learning & 0.532 \\
Relationships between co-workers & 0.435 \\
A wide network of inter-organizational relations & 0.915 \\
The intensity of inter-organizational cooperation & 0.681 \\
An atmosphere of openness in the relationship between co-operators & 0.346 \\
Orientation towards self-development and organizational improvement & 0.565 \\
Voluntarism & 0.436 \\
Low degree of standardization & 0.517 \\
Low degree of formalization & 0.107 \\
Predominance of horizontal interaction in the communication, coordination, and control & 0.192 \\
Predominance of the hierarchy of goals rather than positions & 0.194 \\
\hline
\end{tabular}

According to the research of Mohammad Esmaeil, Gholipour, and Jazavi (2009), there is a negative and significant relationship among vertical separation, a high degree of formalization and centralization with organizational learning. This research is related to the Ministry of Science, Research and Technology in Tehran (Mehrabi et al., 2013). In addition, Martínez-León and Martínez-García (2011) conducted a study in Spanish companies. Although structural modeling did not show any significant relationship between organizational structure and the processes of organizational learning (this result is surprising in view of the model proposed above), the clustering approach proved that organic structural profile helps favor organizational learning and greater knowledge creation rather than mechanics profile. Therefore, finally, the study of Martínez-León and Martínez-García (2011) shows that organizational learning varies according to the kind of structure (organic and mechanistic). The authors have drawn a conclusion that there is no simplistic linear relationship between structure and organizational learning, however, it seems likely that the limited study sample (only 138 companies) made it impossible to construct a proper structural model. Mehrabi et al. (2013) investigated the relationship between organizational structure and dimensions of learning organizations. The study was conducted in the Education Organization in Borujerd County and in the related departments. The results of Pearson correlation coefficient test show that there is a significant and negative relationship between organizational structure (formalization, complexity, and centralization) and fulfillment degree of learning organizations (this relationship is significant for all the dimensions of the learning organization). The studies of Rebelo and Gomes (2011) highlight that an organic structure is an organizational characteristic having a positive and significant relationship with learning culture (the authors also used the correlation method). In addition, Su, J. Li, Yang, and Y. Li (2011), based on a survey of 365 Chinese organizations, found out that exploratory learning and exploitative learning are substitutes, when the organizational structure is mechanistic; that they are complementarities, when the organizational structure is organic, which are the results of the regression analysis.

The empirical studies confirm that the learning of contemporary organizations is promoted by organic structural solutions in all dimensions: complexity (Zgrzywa-Ziemak, 2009; Hao et al., 2012; Mehrabi et al., 2013); standardization (Zgrzywa-Ziemak, 2009; Mehrabi et al., 2013); formalization (Martínez-León \& 
Martínez-García, 2011; Su et al., 2011; Mehrabi et al., 2013); specialization (Zgrzywa-Ziemak, 2009; Martínez-León \& Martínez-García, 2011; Su et al., 2011; Mehrabi et al., 2013); and centralization (Martínez-León \& Martínez-García, 2011; Su et al., 2011; Hao et al., 2012; Mehrabi et al., 2013). The studies have been conducted in different cultural contexts (mainly in Europe and Asia), in different organizations in terms of industry, size and ownership, and profit oriented and non-profit.

It is worth noting that there is a change of the basic role of structures here. Instead of minimizing the freedom and unpredictability of organizational behaviour, the structure will be designed to ensure maximum freedom of action of the organizational participants - the participants, characterized by specific skills and knowledge, wanting to get involved in the emerging tasks. As a result, these structures are characterized by a very high diversity and flexibility, so they are conducive to a rapid reading of changes in the environment, creating new knowledge and implementing the knowledge that is the most adequate under the given operational circumstances. The use of multiple horizontal and vertical organizational links in organic structures creates good conditions for the learning of organizations. Horizontal relations - communication and cooperation-are the basis of diffusion of knowledge and experience. Moreover, cooperative relations lead through the process of externalization and combination of knowledge to the creation of new knowledge - useful for cooperation. However, in the OLC model, the organic structure is the element mobilizing the variability of organization. Therefore, structures are not conducive to memorization of the knowledge created - to do this, non-structural solutions have to be developed.

\section{IT and KM Impact on Organic Organizational Structure}

It is worth looking at the organizational structure in the context of OLC and defining what are the factors that may influence its reorganization into more organic-type one. Theory describing factors that influence organizational structure are very complex. Most authors listed at least several structure-building factors. The most common, obtained from Leavitt's organizational model (1965), are: strategy, employees, technology, and environment. Taking into account the fact that nowadays it is a common knowledge that organizational structures are reorganizing into more organic-type ones, the authors concentrated on factors known to influence organizational structure shift in that way. This article is focusing on IT and KM as two factors that may influence organizational structure.

\section{IT Impact on Organizational Structure}

IT in organization is considered as a group of IT systems (used by employees in organization) with implemented set of IT functions. Since the 70s of the last century, researchers were convinced that there are a number of factors which influence whether the technology will be adopted in the organization or not. In the 80s, they directed their efforts towards creating a method that would allow to predict the dissemination of technology in the organization. In the context of IT, dissemination will be understood as the extent in which they are applied in the organization. The accessibility of IT in the organization is understood as the number of members of the organization having access to these technologies. It is worth noting here that the count is the number of unique visitors - individuals with access to IT. Thus, regardless of what the frequency of technology use is (if they do not use it at all, use once a month, or use several times a day), each user is counted once and only once. Therefore, it considers members who have access to IT, but do not necessarily use it. The next step was to develop methods that allow to specify how many users actually use IT in their work. That was the 
genesis of the concepts of IT acceptance. It has allowed to take into consideration the imbalance between the number of users who have access to IT and the number of users actually using it. IT acceptance, understood as a demonstrable willingness within a user group to employ IT for the tasks it is designed to support (Dillon, 2001), will be a variable use in this publication to characterize IT in organizations.

Direct relations between IT and OLC are not considered as a certainty. Some authors concluded that IT has the potential to both enable and disable OLS. So it can be concluded that IT in organization is a valuable factor influencing OLC: OLC is enhanced through support of communication and provided by IT. Pentland (1995) suggested that introducing an information system can have more profound effects that merely altering the storage, retrieval, distribution, or richness, of information. These basic information processing enhancements are well known and should, in theory, affect organizational learning.

However, because of lack of reliable evidence of significant direct relation between OLC and IT in current studies, this study is aimed at linking IT influence on OLC through organizational structure. IT is considered by many authors as the main source and carrier of change in organizational structure (Wang \& Ahmed, 2003). Therefore, it is worth considering the role of IT in reorganizing to more organic structure, which is one of the important factors affecting organization learning capability.

Most common opinion among authors is that IT reorganizes the communication channels within the organization (making it easier for employers to communicate directly). IT contributes to several changes in organizational structure. Several of them are listed as conclusions in many papers analyzing IT-those below can be considered as the most important ones (Jones \& Dewett, 2001; Spanos, Prastacos, \& Poulymenakou, 2000):

- reduction of the number of administrative employees and middle management employees mainly caused by a more efficient exchange of information;

- increase of self-reliance, due to better access to information among employees using IT, which contributes to the increase of the average span of management;

- increase of information synergy on the lower levels of management, which leads to the situation, in which employees are better equipped to make the right decisions in place, in which the problem arises;

- willingness among managers to delegate decisions to lower levels of the hierarchy, due to the fact that employees acquire additional skills and knowledge while using IT;

- emergence of intelligent formalization effect, which allows employers to communicate and exchange information in codified way, which at the end contributes to unification and organization of documents and procedures;

- reduction of negative effects of specialization due to work enrichment and increased self-reliance of employees.

\section{Relation Between IT Acceptance and Organizational Structure}

Relations between IT and organizational structure were tested in third part of studies, conducted in 2012 (as a part of Ph.D. thesis by Tworek in 2014). One hundred and five organizations were examined (they were different in terms of size, industry, and ownership structure). All of these organizations have implemented IT systems (they were different in terms of dissemination, user acceptance, and type, construed as number and nature of implemented IT function) and claimed that IT is used, among others, to support organization learning. 
To investigate the results of the relation between IT and organizational structure, the key variables describing four organizational structure dimensions were defined: hierarchy, centralization, formalization, and specialization. Subjective level of each variable was calculated as the arithmetic mean of grades given to each item describing one of four variables. Items were put in form of statements and they were rated by the respondents with Likert scale (five items scale) (list of items - statements - for each variable is included in Table 3). It is worth noting that Cronbach's $\alpha$ was 0.641 and higher for every variable, which indicates a high internal reliability of the scales and measurements.

Table 3

Items of Organizational Structure Dimensions

\begin{tabular}{|l|l|l|l|}
\hline Hierarchy & Centralization & Formalization & Specialization \\
\hline $\begin{array}{l}\text { Organizational structure is } \\
\text { complicated. }\end{array}$ & $\begin{array}{l}\text { Decisions concerning response to } \\
\text { environment change are made on } \\
\text { highest hierarchy level. }\end{array}$ & $\begin{array}{l}\text { Number of organizational } \\
\text { documents is high. }\end{array}$ & $\begin{array}{l}\text { Tasks are simple and } \\
\text { repetitive. }\end{array}$ \\
\hline $\begin{array}{l}\text { Number of hierarchy levels is } \\
\text { high. }\end{array}$ & $\begin{array}{l}\text { Decisions concerning intellectual } \\
\text { capital are made on highest } \\
\text { hierarchy level. }\end{array}$ & $\begin{array}{l}\text { Degree of documents details } \\
\text { is high. }\end{array}$ & $\begin{array}{l}\text { Number of production } \\
\text { workers is high. }\end{array}$ \\
\hline $\begin{array}{l}\text { Number of direct subordinates of } \\
\text { managers is high. }\end{array}$ & $\begin{array}{l}\text { Decisions concerning } \\
\text { manufacturing technologies are } \\
\text { made on highest hierarchy level. }\end{array}$ & $\begin{array}{l}\text { Number of regulations } \\
\text { concerning ways of } \\
\text { accomplishing tasks is high. }\end{array}$ & $\begin{array}{l}\text { Number of non-production } \\
\text { works is high. }\end{array}$ \\
\hline $\begin{array}{l}\text { Managers will not be able to } \\
\text { manage more subordinates than } \\
\text { they are managing now. }\end{array}$ & $\begin{array}{l}\text { Operational decisions are made } \\
\text { in place of the problem. }\end{array}$ & $\begin{array}{l}\text { Regulations concerning } \\
\text { employees' communication } \\
\text { are formal and restricted. }\end{array}$ & Task rotation is common. \\
\hline
\end{tabular}

IT was described by degree of IT acceptance in organization. Subjective level of IT acceptance was calculated based on a set of statements prepared on basis of IT acceptance measuring method proposed by Davis (1989) - set of statements and detailed information were published by Tworek and Martan (2015). Additionally, Cronbach's $\alpha$ was calculated for this scale — it came back as 0.905 , which indicates very high internal reliability of scale.

Firstly, correlation analysis using Pearson coefficient was done. Analysis has indicated that there is indeed the correlation between IT acceptance and hierarchy complexity, degree of centralization, formalization, and specialization, which may indicate that with increase of IT acceptance, the organizational structure changes into more organic-type one (hierarchy is less complex and centralization, formalization and specialization degree is smaller).

Secondly, stepwise regression analysis was performed. Fitting models were obtained for hierarchy ( $F$ $(4.99)=14.585, p<0.001)$, formalization $(F(3.100)=8.357, p<0.001)$, and specialization $(F(4.99)=23.145$, $p<0.001$ ). IT acceptance proved to be a significant independent variable with every obtained model (Figure 2 and Table 4). IT acceptance proved to be the only significant independent variable in model obtained for centralization $(F(1.102)=9.690, p<0.05)$. This model cannot be characterized as fitting-obtained predictors explained only $7.8 \%$ of the variance of the dependent variable. Regression analysis has shown that with increase of IT acceptance, there is a significant change in each variable characterizing organizational structure. Hierarchy complexity declines, as the degree of centralization, formalization, and specialization do. It confirms that organizational structure becomes a more organic-type one. 


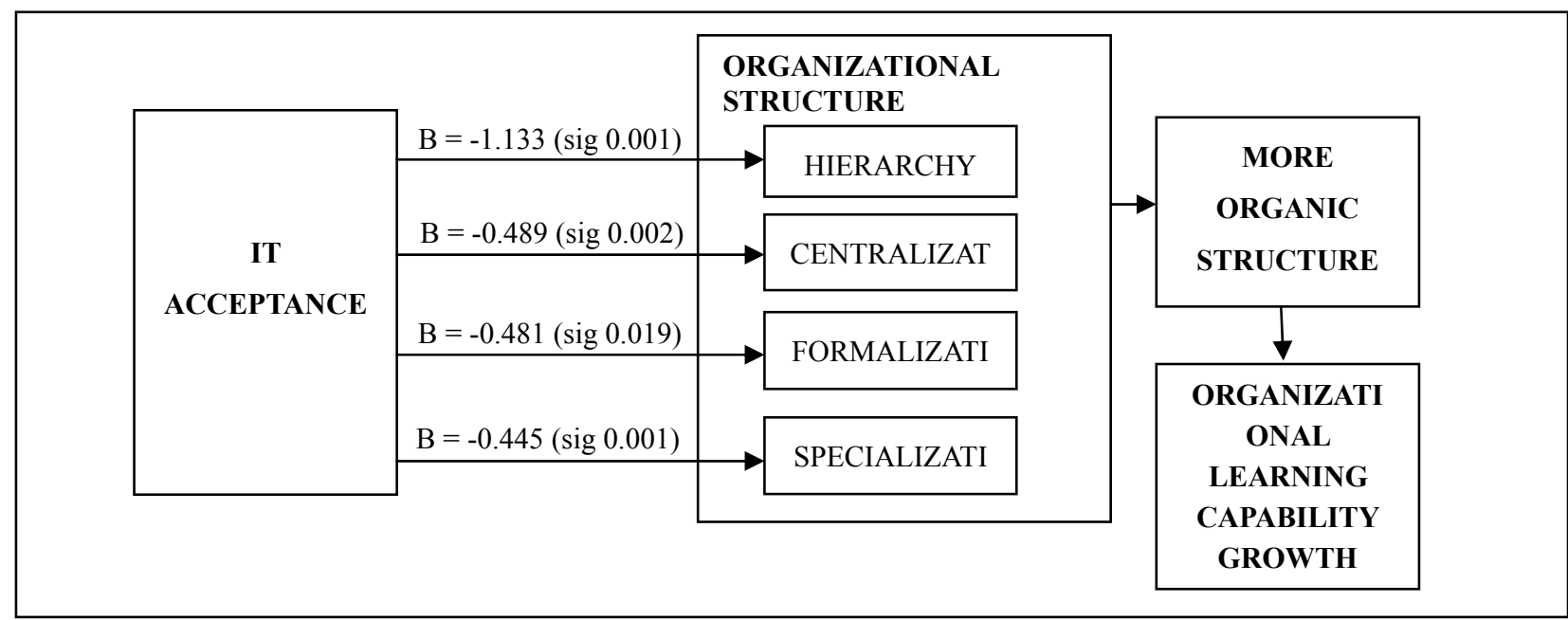

Figure 2. IT influence on organizational structure.

Table 4

Regression Analysis Between Organizational Structure and IT Acceptance

\begin{tabular}{llcccc}
\hline \multirow{2}{*}{ Independent variable in regression models } & \multicolumn{4}{c}{ Dependent variable in regression model } \\
\cline { 3 - 6 } & $B$ & $\begin{array}{l}\text { 1st model: } \\
\text { hierarchy }\end{array}$ & $\begin{array}{l}\text { 2nd model: } \\
\text { centralization }\end{array}$ & $\begin{array}{l}\text { 3rd model: } \\
\text { formalization }\end{array}$ & $\begin{array}{l}\text { 4th model: } \\
\text { specialization }\end{array}$ \\
\hline \multirow{4}{*}{$\begin{array}{l}\text { Information technology } \\
\text { acceptance }\end{array}$} & -1.133 & -0.489 & -0.481 & -0.426 \\
& Standardized error & 0.193 & 0.150 & 0.201 & 0.129 \\
& Beta & -0.538 & -0.356 & -0.248 & 0.277 \\
& $T$-student test & -5.884 & -3.262 & -2.396 & -3.303 \\
& Significance & 0.001 & 0.002 & 0.019 & 0.001 \\
& Significant element of & Yes & Yes & Yes & Yes \\
\hline
\end{tabular}

\section{KM Processes Impact on Organic Organizational Structure}

The relationship between $\mathrm{KM}$ and OLC is being discussed. There were opinions that the overlapping nature of KM and OLC makes it difficult to differentiate among these concepts and that OLC is the precursor of KM (Mishra \& Bhaskar, 2011). Nowadays, the researchers provide evidence to support the statement that these concepts are interrelated and interdependent, but distinct (Karkoulian et al., 2013). What is more, according to empirical research, KM significantly affects organizational learning (Nafei, 2014) and, although $\mathrm{KM}$ with OLC is a mutually self-supporting phenomenon, KM enhances learning organization more than that learning organization enhances KM (Karkoulian et al., 2013). The relationship between KM and OLC has not been verified yet, but it can be assumed that there is a significant relationship among these concepts and that KM has important impact on OLC.

The necessity of effective KM, recognized as a strategic corporate asset, is forcing changes in work organization. The transformation of modern enterprises in knowledge-based organizations is its consequence. This requires actions undertaken in different areas of the organization, aimed (on the highest level of generality) at providing a competitive advantage through the development of knowledge and skills. It happens because of organizational culture that supports the acquisition and sharing of knowledge, the design of structures and procedures to ensure the collection and use of knowledge, the acquisition of knowledge from the environment market and use of IT systems, which allow to codify, collect, and share knowledge among members of the 
organization. $\mathrm{KM}$ is manifested in actions supporting specific processes of knowledge: localization and acquisition, codification, transfer, and finally use of knowledge. They form a logical sequence of events: The acquisition or development of knowledge occurs before recording and codifying good solutions. Codification provides access to knowledge, thereby, it increases the degree of dissemination of transferred knowledge. The last element is the use of knowledge that occurs as a result of use of the increased competence of employees and the organization as a whole. This leads to the closing of the cycle, as an organization, with the new knowledge, may see new possibilities of its creation and development.

Activities within the subsequent KM processes affect the elements of the organization, including the dimensions of the organizational structure, especially the formalization, standardization, and centralization level. It is important to point out that in order to acquire and develop knowledge, there are mergers of departments and individuals taking place in the organization. The mergers may be temporary and reorganize structure towards more flexible forms. Employees are expected to be intellectually committed. Subjective approach to employees has to be encouraging, should mobilize them to ingenuity, and promote self-organization at the same time. The knowledge acquired and developed at an early stage must then be structured and stored - it is the purpose of codification, which allows to understand the relationships among data, its identification, and documentation of rules governing data management. It also ensures the integrity and relevance of the data-basing on the principles and procedures. Codification of knowledge and mapping its sources can affect the reduction in the level of formalization - eliminating data redundancy and allowing access to data in electronic form by many people at the same time. However, when organizational processes are standardized and documented, knowledge replication is easier (such as hand-offs and specs).

Transfer of knowledge is aimed at reducing the incidence of not using knowledge by the organization. It requires the identification of areas, from which it can be freely acquired and clear rules of its location. The organizations, which adopt flexible and increasingly flat organizational forms with fewer hierarchical levels, are better at transferring knowledge. This makes it possible for employees to take better advantage of their competencies, generating organizational routines and increasing the value of their contributions thanks to the freedom of action they are given (Claver-Cortes, Zaragoza-Saez, \& Pertusa-Ortega, 2007). The ability of sharing and distributing knowledge resources across functional boundaries enables the firm to fundamentally change its business processes. The sharing of knowledge resources not only facilitates cross-functional interaction but also allows the sharing of knowledge repositories among process participants, thereby allowing greater collaboration and understanding of the entire process rather than having fragmented parts of the process (Liao, Chuang, \& To, 2011). Transfer of knowledge includes two forms: formal (IT can be used to transfer explicit knowledge (workflow)) and informal (which is based on the assumption that the simplest and most effective form of knowledge transfer is direct and free contact between employees). In organizations which manage their knowledge, it is common to observe shorter communication channels to facilitate the rapid transfer of knowledge. Knowledge sharing and the availability of required knowledge empower employees at the lower level of organizational hierarchy may encourage them to participate in more decision-making activities than they would, otherwise this tendency would result in a more decentralized organizational structure (Liao et al., 2011).

Until the actual use of knowledge, codification or transfer is useless (Argote, McEvily, \& Reagans, 2003) - economization of knowledge occurs only while the knowledge is being used. This process of KM is also a source of good practices that should arise from reporting after acting. The capability to utilize knowledge base on decision making and problem solving allows organization to respond more effectively to environmental 
changes, which, in turn, has an impact on the level of decentralization-KM supports decreasing centralization (Liao et al., 2011; Binney, 2001).

Conscious KM requires setting targets (especially strategic) and building optimal organizational structures that allow to locate and access multiple sources of knowledge, flexible and free flow of information, and making measurements. KM is based on the free interaction of employees, working in flexible teams - these elements are positively correlated with structure, which is less formalized, more decentralized, and integrated (Chen, Huang, \& Hsiao, 2010).

\section{Relation Between KM and Organizational Structure}

The studies (Walecka-Jankowska, 2011), which allowed for research relation between KM and organizational structure, during the research of 105 organizations, were examined (they were different in terms of size, industry, and ownership structure). One questionnaire was sent to each surveyed organization with the request that a person with a broad view of the whole organization (i.e., chief executive office, management team, quality specialist, etc.) filled in.

KM was described by degree of four knowledge processes: acquisition and creation, codification, transfer, and utilization of knowledge - set of statements and detailed information were published in Walecka-Jankowska's study (2011). Additionally, Cronbach's $\alpha$ was calculated for this scales - it came back as 0.886 (acquisition and creation), 0.934 (codification), 0.843 (transfer), and 0.889 (utilization) which indicates very high internal reliability of all four scales.

To investigate the results of the relation between KM and organizational structure, the key variables were defined: degree of specialization, formalization, standardization, centralization, and hierarchy coded in 10 items (Table 5).

Table 5

Organizational Structure Items

\begin{tabular}{|l|l|l|l|l|}
\hline Hierarchy & Centralization & Formalization & Specialization & Standardization \\
\hline $\begin{array}{l}\text { Number of managerial } \\
\text { positions is high. }\end{array}$ & $\begin{array}{l}\text { Decisions concerning } \\
\text { strategic problems are } \\
\text { made on highest } \\
\text { hierarchy level. }\end{array}$ & $\begin{array}{l}\text { Number of } \\
\text { organizational } \\
\text { documents is high. }\end{array}$ & $\begin{array}{l}\text { Tasks are simple and } \\
\text { repetitive. }\end{array}$ & $\begin{array}{l}\text { Number of standard } \\
\text { procedures is high. }\end{array}$ \\
\hline $\begin{array}{l}\text { Number of hierarchy } \\
\text { levels is high. }\end{array}$ & $\begin{array}{l}\text { Operational decisions } \\
\text { are made in place of the } \\
\text { problem. }\end{array}$ & $\begin{array}{l}\text { Degree of documents } \\
\text { details is high. }\end{array}$ & Number of jobs is high. & $\begin{array}{l}\text { Adherence to the } \\
\text { specific procedures is } \\
\text { required. }\end{array}$ \\
\hline
\end{tabular}

Table 6

Regression Analysis Between Organizational Structure and KM

\begin{tabular}{|c|c|c|c|c|c|c|}
\hline \multirow{2}{*}{\multicolumn{2}{|c|}{$\begin{array}{l}\text { Independent variable in regression } \\
\text { models }\end{array}$}} & \multicolumn{5}{|c|}{ Dependent variable in regression model } \\
\hline & & $\begin{array}{l}\text { 1st model: } \\
\text { configuration }\end{array}$ & $\begin{array}{l}\text { 2nd model: } \\
\text { centralization }\end{array}$ & $\begin{array}{l}\text { 3rd model: } \\
\text { formalization }\end{array}$ & $\begin{array}{l}\text { 4th model: } \\
\text { specialization }\end{array}$ & $\begin{array}{l}\text { 5th model: } \\
\text { standardization }\end{array}$ \\
\hline \multirow{6}{*}{$\begin{array}{l}\text { Knowledge } \\
\text { management }\end{array}$} & $B$ & 0.002 & 0.047 & 0.071 & -0.022 & 0.102 \\
\hline & \multicolumn{2}{|c|}{ Standardized error 0.033} & 0.023 & 0.033 & 0.030 & 0.025 \\
\hline & Beta & 0.005 & 0.195 & 0.210 & -0.071 & 0.368 \\
\hline & $T$-student test & 0.047 & 2.018 & 2.176 & -0.722 & 4.018 \\
\hline & Significance & 0.962 & 0.046 & 0.032 & 0.472 & 0.001 \\
\hline & $\begin{array}{l}\text { Significant } \\
\text { element of } \\
\text { regression model }\end{array}$ & No & Yes & Yes & No & Yes \\
\hline
\end{tabular}


Firstly, correlation analysis was done. Analysis has indicated that there is indeed the correlation between $\mathrm{KM}$ processes and degree of formalization, standardization, and centralization. After confirming internal reliability of each scale and normal distribution for each variable, correlation and regression analysis were done. Results of regression analysis are presented in Table 6.

Models were obtained for centralization $(F(1.103)=4.072, p<0.01)$, formalization $(F(1.103)=4.737$, $p<0.01)$, and standardization $(F(1.103)=16.148, p<0.001)$. For specialization and configuration, there is $p>0.01$. Regression analysis has shown that with increase of KM processes, there is a significant change in three variables characterizing organizational structure. Standardization, as the degree of centralization and formalization do, is decreasing. It confirms that organizational structure becomes a more organic-type one.

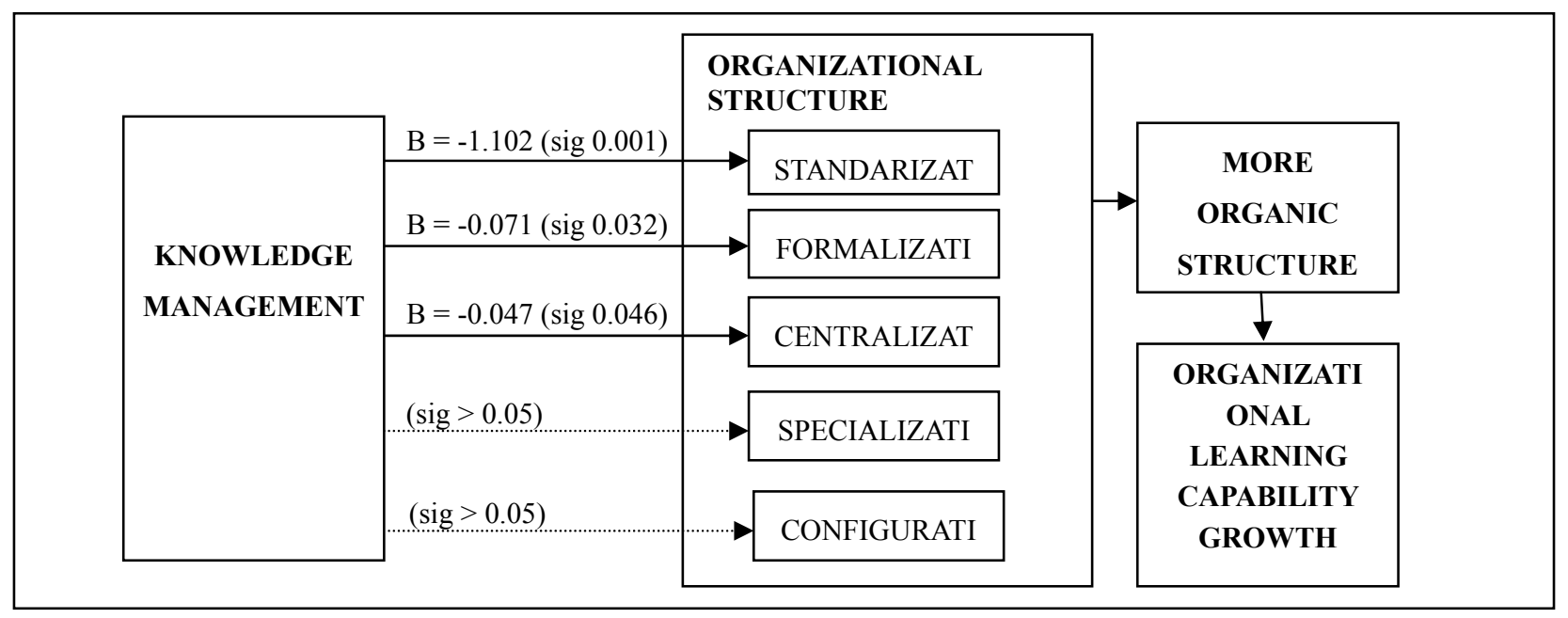

Figure 3. KM processes influence on organizational structure.

\section{Conclusions}

The empirical studies confirm theoretical views that the learning of contemporary organizations is promoted by organic structural solutions in all dimensions (complexity, standardization, formalization, specialization, and centralization). OLC development, however, requires the selection of such instruments of shaping the organic structural solutions that will increase the freedom of action of organizational members by increasing access to information and knowledge, promoting the transfer of information and knowledge, supporting the development of new knowledge, and using it in action. Authors identified two complimentary factors which may contribute to structure reorganization: IT in organization and KM.

Conducted research has shown that IT indeed impacts organizational structure and contributes to reorganizing structure less complex, with lower degree of centralization, formalization, and specialization. It can be concluded that the research provides evidence that in fact there is an increase of self-reliance among employees using IT, which contributes to the increase of the average span of management and results as lower centralization level and less complex structural hierarchy in organizations with highest IT acceptance. However, centralization, which is getting lower with increasing IT acceptance, can be primarily the evidence of incensement of information synergy on the lower levels of management-the effect most desired in organizations trying to enhance their learning capability. This increasing of IT acceptance leads to the situation, in which employees are in fact better equipped to make the right decisions in place, in which the problem arises and results with lower degree of centralization. Therefore, it can be concluded that increasing IT acceptance can 
in fact contribute to reorganizing structure into a more organic-type one.

Except IT, the research has shown that KM also impacts organizational structure, pushing it in the direction of more organic forms. The reduction in the level of formalization and standardization as well as the increasing decentralization of the organization is especially noticeable. Process of codification, which is connected, i.e., with information and knowledge source mapping, can affect decreasing of formalization level. Besides that, KM reduces length of communication channels, which with enabling access to the many different sources of knowledge encourages employees to participate in decision-making, lowering the level of centralization. The last process, closing the knowledge process circle (utilization), is directly connected with decentralization, because it causes employees to solve problems by themselves. KM accompanied by IT acceptance gives employees tools to acquire the necessary knowledge to do so.

Analysis of presented researches can lead to an additional conclusion. The combination of measures used in the field of KM and acceptance of IT contributes to reorganization of structure and changes in most of the structure dimensions in the direction of more organic solution, which may indicate the compatibility of the two factors in the development of organic structure IT acceptance and KM processes. Influence on organizational structure is presented in Figure 4.

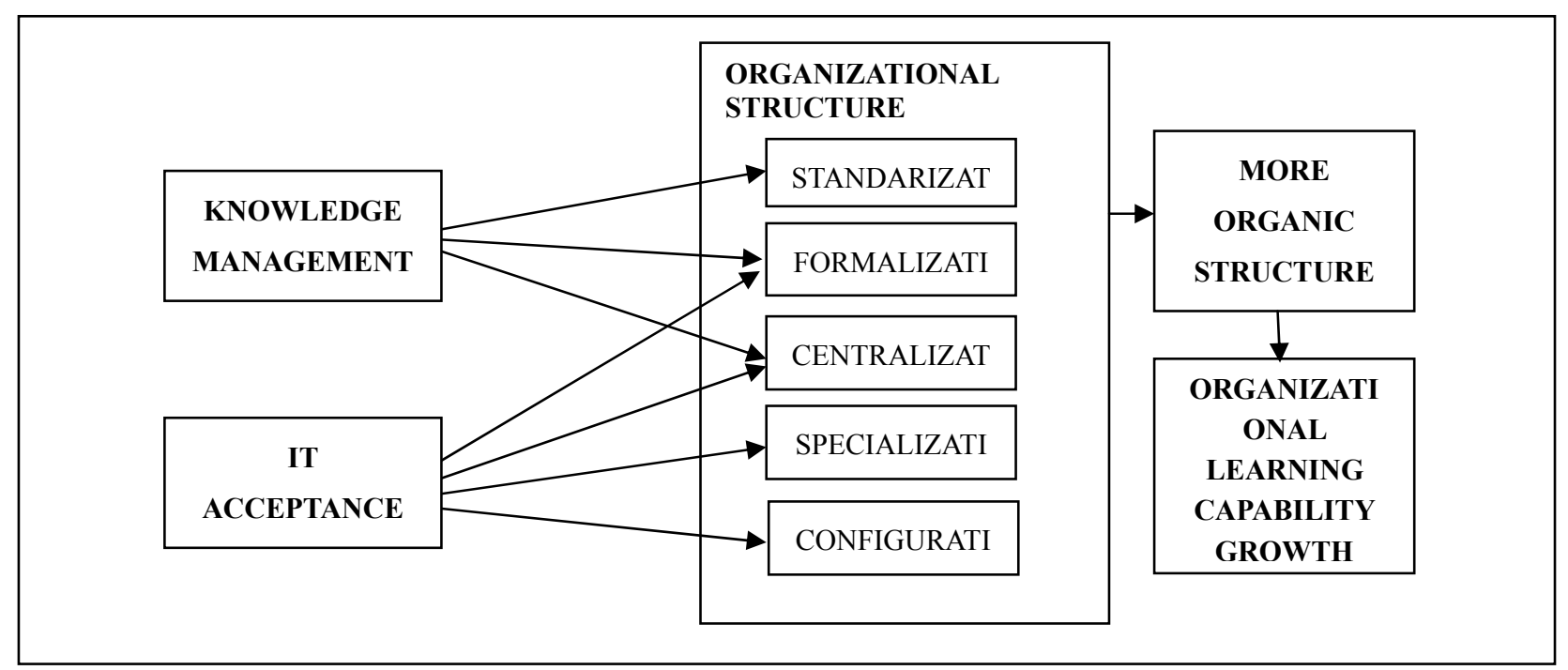

Figure 4. IT acceptance and KM processes influence on organizational structure.

Compatibility of both factors may be present due to the fact that IT gives the tools to support KM processes - often being key to obtaining, collecting, transparent cataloging, and providing access to relevant knowledge resources at all levels of the organizational structure. KM enables the use of IT, but also relates the knowledge with employees. Perhaps the approach based on employees and their immediate contacts allows effective use of technology, which is not in itself a carrier of knowledge but a tool to store codified knowledge and allow contact among employees affecting reorganization of structure into more organic-type one (Binney, 2001). However, this conclusion requires verification by building a single model which takes into account variables, such as IT, KM, and organization structure.

Concluding, it can be noticed that IT and KM have significant impact on organizational structure. They both can contribute to reorganization of organizational structure to a more organic-type one. Because of that, they may be the intermediate factor influencing the OLC. 


\section{References}

Argote, L., McEvily, B., \& Reagans, R. (2003). Managing knowledge in organizations: An integrative framework and review of emergent themes. Management Science, 49, 571-582.

Binney, D. (2001). The knowledge management spectrum-Understanding the KM landscape. Journal of Knowledge Management, 5(1), 33-42.

Burns, T., \& Stalker, G. M. (1961). The management of innovation. Tavistock: Oxford University Press.

Chen, C. J., Huang, J. W., \& Hsiao, Y. C. (2010). Knowledge management and innovativeness: The role of organizational climate and structure. International Journal of Manpower, 31(8), 848-870.

Claver-Cortes, E., Zaragoza-Saez, P., \& Pertusa-Ortega, E. (2007). Organizational structure features supporting knowledge management processes. Journal of Knowledge Management, 11(4), 45-57.

Davis, F. D. (1989). Perceived usefulness, perceived ease of use and user acceptance of information technology. MIS Quarterly, 13(3), 319-340.

DeFillippi, R. J. (2002). Organizational models for collaboration in the new economy. Human Resource Planning, 25(4), 7-18.

Dillon, A. (2001). User acceptance of information technology. In W. Karwowski (Ed.), Encyclopedia of human factors and ergonomics. London: Taylor and Francis.

Dodgson, M. (1993). Organizational learning: A review of some literatures. Organizational Science, 14(3), 375-394.

Fiol, C. M., \& Lyles, M. A. (1985). Organizational learning. Academy of Management Review, 10(4), 803-813.

Galunic, D. C., \& Eisenhardt, K. M. (2001). Architectural innovation and modular corporate forms. Academy of Management Journal, 44(6), 1229-1249.

Goh, S. C., Elliott, C., \& Quon, T. (2012). The relationship between learning capability and organizational performance. Meta-analytic examination. The Learning Organization, 19(2), 92-108.

Hao, Q., Kasper, H., \& Muehlbacher, J. (2012). How does organizational structure influence performance through learning and innovation in Austria and China. Chinese Management Studies, 6(1), 36-52.

Jones, G. R., \& Dewett, T. (2001). The role of information technology in the organization: A review, model, and assessment. Journal of Management, 27, 313-346.

Karkoulian, S., Messarra, L. C., \& Mccarthy, R. (2013). The intriguing art of knowledge management and its relation to learning organizations. Journal of Knowledge Management, 17(4), 511-526.

Lazonick, W. (2005). The innovative firm. New York: Oxford University Press.

Leavitt, H. J. (1965). Applied organizational change in industry: Structural, technological and humanistic approaches. In J. G. March (Ed.), Handbook of organizations. New York: Rand McNally and Company.

Liao, C., Chuang, S. H., \& To, P. L. (2011). How knowledge management mediates the relationship between environment and organizational structure. Journal of Business Research, 64(7), 728-736.

Martínez-León, I. M., \& Martínez-García, J. A. (2011). The influence of organizational structure on organizational learning. International Journal of Manpower, 32(5/6), 537-566.

Mehrabi, J., Soltani, I., Alemzadeh, M., \& Jadidi, M. (2013). Explaining the relationship between organizational structure and dimensions of learning organizations (Case study: Education organization in Borujerd County and the related departments). International Journal of Academic Research in Business \& Social Sciences, 3(4), 116-128.

Mishra, B., \& Bhaskar, A. U. (2011). Knowledge management process in two learning organizations. Journal of Knowledge Management, 15(2), 344-359.

Mohammad Esmaeil, S., Gholipour, A., \& Jazavi, E. (2009). Studying the relationship between organizational structure of central libraries related to Ministry of Science, Research and Technology in Tehran and their degree of adaptation with characteristics of learning organizations. Basirat Journal, 40, 104-120.

Nafei, W. (2014). The mediating effects of organizational learning on the relationship between knowledge management and organizational performance: An applied study on the Egyptian commercial banks. International Journal of Business and Management, 9(2), 244-261.

Nonaka, I., \& Takeuchi, H. (1995). The knowledge-Creating company. New York: Oxford University Press.

Pentland, B. T. (1995). Information systems and organizational learning: The social epistemology of organizational knowledge systems. Accounting, Management and Information Technologies, 5(1), 1-21.

Popper, M., \& Lipshitz, R. (1998). Organizational learning mechanisms: A structural and cultural approach to organizational learning. The Journal of Applied Behavioral Science, 34(2), 161-179. 
Rebelo, T. M., \& Gomes, A. D. (2011). Conditioning factors of an organizational learning culture. Journal of Workplace Learning, 23(3), 173-194.

Sakalas, A., \& Venskus, R. (2007). Interaction of learning organization and organizational structure. Engineering Economics, $3(53), 65-70$.

Santos-Vijande, M. L., López-Sánchez, J. Á., \& Trespalacios, J. A. (2012). How organizational learning affects a firm's flexibility, competitive strategy, and performance. Journal of Business Research, 65(8), 1079-1089.

Spanos, Y., Prastacos, G., \& Poulymenakou, A. (2000). The impact of information and communication technologies on firm structure: Evidence from an economy in transition. ICMIT, 2, 573-579.

Su, Z., Li, J., Yang, Z., \& Li, Y. (2011). Exploratory learning and exploitative learning in different organizational structures. Asia Pacific Journal of Management, 28(4), 697-714.

Tworek, K. (2014). Information technology influence on organizational structure (Ph.D. thesis, Wroclaw University of Technology, Wroclaw).

Tworek, K., \& Martan, J. (2015). Suitability analysis of a new method for measuring information technology acceptance. In J. Kowal (Ed.), Information and communication technologies (ICT) in management (pp. 133-148). Newcastle: Cambridge Scholars Publishing.

Walecka-Jankowska, K. (2011). The impact of knowledge management on innovation of enterprises (Ph.D. thesis, Wroclaw University of Technology, Wroclaw).

Wang, C. L., \& Ahmed, P. L. (2003). Structure and structural dimensions for knowledge-based organizations. Measuring Business Excellence, 1(7), 51-62.

$\mathrm{Wu}, \mathrm{L}$. Y. (2010). Applicability of the resource-based and dynamic-capability views under environmental volatility. Journal of Business Research, 63(1), 27-31.

Zgrzywa-Ziemak, A. (2009). Model of OLC in enterprises in view of empirical research. In A. Zgrzywa-Ziemak and R. Kamiński (Eds.), Rozwijanie zdolności uczenia się przedsiębiorstwa (pp. 138-178). Warszawa: DIFIN. 